\title{
The Meaning of "Absence"
}

\author{
The Absence of Characters in Novels and Movies
}

\author{
Hongzeng Ren \\ College of Literature and Journalism \\ Sichuan University \\ Chengdu, China 610064
}

\begin{abstract}
In the history of literature and film, there are many cases of "absence" of characters. Although the characters are not present in the narrative process, this doesn't indicate the lack of the meanings of the absent characters. In the process of reading and watching, the receiver can still perceive the bearing of the symbolized invisible characters through the information expressed in the text.
\end{abstract}

Keywords—absence; presence; symbol; meaning

\section{INTRODUCTION}

The character is the basic element of narrative. When talking about the role of the character, Propp said that "the story often assigns the same action to different characters, which makes it possible for us to study the story according to the function of the character." "In the story, no matter how different the characters are, they often do the same thing. The implementation of the function can be changed, and it is a variable factor... but the function itself is a constant factor." From ancient times to the present, from the East to the West, the narrative literature created by human beings in the history of culture, whether it is "Homer's Epic", "Ancient Greek Tragedy", or "Three Kingdoms", "Journey to the West" and other traditional narrative works based on plot or in modern or post-modern film and television works featuring desalination or deconstruction of the plot, such as "Wild Strawberry" and "Marielbad last year", as long as there is a narrative, the character must exist, or the event must contain characters. However, the status of the characters in the narrative works is not equal. There must be a distinction between the primary and secondary ones, namely the protagonist and the secondary characters as well as supporting roles, and even some characters without names, who just flashed through the whole story. Despite of not a major driving force for narrative, as factors in narrative, the existence of these "persons" is necessary. That is to say, all characters have their functions. The type of people to be discussed in this article has no chance of appearing independently because there is no "entry into the plot". They are often hidden behind the story, not "concrete image". In Simon Chatman's writing "Stories and Discourses," they are known as the "absent" character. Even so, readers and viewers can feel the presence of them through the words and stories of "present" people at every moment.

\section{THE APPEARANCE OF THE PHENOMENON OF "ABSENCE" IN THE NOVEL}

A complete novel contains three basic elements: character, plot, and environment. Narrative must have the participation of characters, and what's more, the characters are the core factor. Correspondingly, character shaping is also the most key task of literary creation. The characters "absent" in the novels are similar to the "shadow figures" alleged by Huang Guangfang. "The 'Shadow Character' is specifically used to refer to the kind of roles that are not described by the narrator directly in the novel narrative and they are always like people's shadow hidden behind characters, but they may burst into the viewers' eyes at any time as the story progresses." In all kinds of stories, 'Shadow Character' 'connected front and rear story units, which explains the origin of the main characters, so that the main characters can appear on the scene calmly.' It can be seen that the shadow character is not a dispensable character in the story, but influence the progress of the main story in an indirect way behind the main storyline in the way of absence, and at any time, according to the needs of the plot, the shadow character will be present or give an invisible 'pushing power'." The "absent" character is also close to what Lu Puling said as "virtual figures." "Virtual figure refers to an actor who does not possess physical nature (such as description of physical characteristics and personality traits, etc.), such as, the recipient in the epistolary novel ("William" in The Sorrows of Young Werther), the editor in preface or postscript to narrative works ('Watson' in the Sherlock Holmes)... These imaginary characters often appear as only one person, such as 'I', without age characteristics, names, and physical characteristics, etc., and even they are non-story factors, but they tend to have important narrative functions."

The characters in the novels that are "absent" are usually male, and their identities are often "father" and "lover". The reason why the image of father and lover are tend to be set to "absence" is more related to the narrative mode of the work and the identity anxiety of the author (female), and more or less critical, centering on the fatherly authority and hegemonic male. Authors of such works are represented by 19th-century British critical realist writers Charlotte Bronte, Jane Austen, and contemporary British writer Ian Russell McEwan. There are similar characters in Chinese modern literature. 
The "absence" of father image: the absence of father's image is a common phenomenon in literary works. Charlotte Bronte's four novels, The Professor, Jane Eyre, Shirley and Villette, have strong autobiographical color. The heroes and heroines in her works have prototypes in real life, and the heroines' experiences can also be traced from the author's life. But unlike Charlotte in reality, the protagonists in the novel have no father. The absence of father image is related to the author's identity anxiety as a female writer. In the novel "The Professor", Charlotte explores the question "What is a woman?", and she concludes that a woman is weakness. "Only men can find a place in society, but women can't, and women are not free. Women can only fall into the trap of secular marriage. They are a group of people who rely on others, from childhood to the end of life. The world is dominated by men." Based on this, Charlotte set her father's image as "absent" in the novel, so that the heroine of the story can obtain relatively loose free space, reducing the restrictions and limitations. In virtue of heroine's perspective and experience, the author aims to express her dissatisfaction and criticism of the patriarchal society.

Ian McEwan's novel "Atonement", which came out in 2001, is highly debated for its strong ecological ethics, social responsibility, political issues, and war trauma. The protagonist of "Atonement" comes from three different families: the Talis aristocratic family consisting of mother Emily, sister Cecilia, brother Leon, and sister Brioni; a family of civilians composed of mother Grace and son Robbie and composition; and a disharmonious family of mothers Hermione, daughter Lola, and twin brothers. The three families have one thing in common: that is, the father is "absent" to varying degrees. In the novel, war is the political and historical background of the father's "absence", which seems to provide a nearly reasonable explanation for "absence". At the same time, it also reveals the irreparable disaster and pain brought by the war to families and individuals. The "absence" of the three fathers is manifested in the form of: being out of family throughout the year, missing and fleeing; in the sense of: lack of paternal love, the broken marriage, and the absence of patriarchy. The "absence" of the father's image symbolically "destroyed" the authority of the father in the traditional sense, and also showed the subversion and deconstruction of the traditional values of the patriarchal society.

Other men's "absence": in addition to the absence of father image, there is also an absence of male of significance. Chinese modern and contemporary female literature with strong feminine self-consciousness has also created impressive "absent" male image. Ding Ling, as a talented woman in the history of modern Chinese literature, holds high the banner of women's consciousness and devotes her brushwork more to the creation of female images, but she also builds a series of "absent" men with skilled artistic genius. The full text of the novel "Yang Ma's Diary" does not have a positive description of Yang Ma's "man", and even does not introduce his name or specific occupation. Only through a few words in Yang Ma's diary, the reader outlines a vague image of "rash man" who cannot afford to raise his wife. It is precisely because this "absent" rash man fails to afford to raise his wife that Yang Ma has to leave home for work. "Summer Vacation" describes the homosexuality of several young female teachers such as Dezhen, Chengshu and Juanzi. There is no male protagonist in the article. If there is a male presence, it is the object of Dezhen's marriage - a man who has no name known by readers. Even just an unnamed man, he cast a stone in their intimate relationship circle, proclaiming that their respected celibacy is going to collapse.

\section{THE APPEARANCE OF THE CHARACTER "ABSENCE" IN THE FILM WORKS}

In literary works, the brushworks cast by the "absent" characters are rare, and they are only presented in a certain chapter and part; the "absence" in the film works as the comprehensive art of audio-visual is more intuitive. Visually, it is manifested as no appearance, not appearing in the lens, or appearing merely in a certain part of the body, in the back, or in a blurring effect; from the hearing, they are from the lines of a certain role in the film, or only appear in the way of voice without a specific image. When talking about the role of this "absence" in the film, Daniel Dayan said: "We are arranged to look with another observer or ghost's eyes, but the role himself is not present. If there is no unique perspective code of lens, there will be no such "absent" one, and the vision we see will not seem to be given by a specific viewpoint. However, classic movies do not simply provide us with a hidden absentee's point of view. Through the alternate design of the classic lens and the inverse lens, the absentee turns into a character, and the visual world of the film will be transformed from expression to fiction as well as a world is not (by a filmmaker, by an ideology system) created artificially but a world that is directly seen."

Absolute absent and no image appears, and the absent characters never be present in the entire narrative text. Suspense master Hitchcock's representative work, Butterfly Dream, shows the director's uniqueness in dealing with "absent" characters. "Absent" character Rebecca is the "suspense" throughout the film. Relatively special is that, Rebecca, who is "absent", is a female figure. The reason for not being present is not intentionally concealed, but due to unnatural death. The young girl played by Joan Fontaine, who is later married Mrs. Derwent, finds that her husband, Maxim Derwent's ex-wife, Rebecca's ghost, often lingers throughout the Mandeli Estate. The mysterious female housekeeper, Mrs. Danvers, also appears to her from time to time as a ghost. After the "absence" set by the director, revealing the true face of Rebecca becomes the main story line promoting the development of the whole story and the audience wants to know urgently how and why all these things happen. Compared with the Derwent couple who lack the distinctive character, it seems that Rebecca is the real protagonist of the film. At the end of the film, the ending is unexpected: the real Rebecca is a beautiful but selfish, cold, profligate siren. It can be said that the "absent" character of Rebecca that does not appear in the "Butterfly Dream" is undoubtedly successful.

Incomplete presence and only partial display of the image: no absolutely direct image, but only some parts of the 
body or back. In domestic films, there are similar cases in which the characters are "absent" such as, the film "Raise the Red Lanterns", which was adapted from "Wives and Concubines" created by Su Tong, directed by Zhang Yimou. In the film, "Master" Chen Zuoqian is a typical "absent" character. The "absence" here is not as thorough as Rebecca in "Butterfly Dream", but it is a vague image of small vision, back, part of the body, and sound, creating an effect that "only the sound can be heard", which is a pretty meaningful modification to the image of Chen Zuoqian in the original work. In the early stage of the filming, the film crew took a close-up shot of "Master Chen " (Ma Jingwu played), but in the later editing process, these shots of "having face" were deleted in order to create a kind of " mysterious" "absence". Therefore, the audience, even at the end of the film, did not know what the "Master Chen" looked like. "Bodyguards and Assassins" directed by Chen Desen and produced by Chen Kexin, showed at the end of 2009 did not give the player Zhang Han too many performance chances to shape "Sun Yat-sen", a great historical figure. Only at the end of the film, a face has been dressed was showed so that audience did not recognize it, but guessing that from the sound and shape the actor was Zhang Hanyu. The role of "Sun Yat-sen" in the film can be said to be very important. It is this character that leads to two plot clues: assassination and protection. However, only a few shots in the film showed the character image from the back, and the sound also plays a role in shaping. In this sense, in the entire film, "Sun Yat-sen" is almost "absent", only in the last part having a lens to achieve "presence." In the words of Zhang Han himself: "Sun Yatsen" in the film is just a spiritual symbol. In the end, should "Sun Yat-sen" "show face"? Which treatment is better for "show and not show"? At the time, a heated discussion was caused inevitably.

Similar artistic processing techniques can be seen in some other movies, such as In the Mood for Love directed by Wang Kar-wai. Su Lizhen's husband and Zhou Muyun's wife face the audience only with their voice, back or part of their bodies, and become "absent" couples. However, it is the existence and behavior of the "first cheaters" who are dealt with by "blurring" that determine the emotional entanglement and joy as well as sorrow between Zhou and $\mathrm{Su}$, forming the mutual contrast between the "absent" and "present" characters. In 2017, in the vast war scene of the World War II-related film "Dunkirk" directed by Christopher Nolan, although there is no image of German generals and soldiers, but the fierce firepower shot at the Allies, sacrificed soldiers, the planes are shot down and the bombed ships are all showing the strong presence of the Germans.

\section{The MEANING OF THE PRESENCE OF "ABSENT" CHARACTERS}

The characters mentioned in the above are not actually and clearly present, and they have become a kind of "feeling with meaning" and a "symbol". The purpose of the symbol is to express meaning, and the symbol that fails to express meaning does not exist. So where does the meaning of the symbols in the text come from? Zhao Yiheng believes that "the meaning (of symbol) is not present (not yet explained) and is present (must be explained). The meaning has not yet been explained (the necessity of not being present beforehand), so that the symbolic activity can be carried out in the direction of interpretation; the meaning must be able to get an explanation (the final presence of the certainty), so that the receiver can stand at the position of interpretation; once the receiver sees a perception as a symbol, it becomes the object of interpretation, and once the symbol becomes the object of interpretation, it must be meaningful: the interpreter's interpreting intention makes the symbol carry meaning." As the reader and the audience receive the text, the "unexplained meaning" is finally implemented as "presence". Although the characters in the novel texts and film and television works are "absent" in different forms, readers and viewers can feel the implicit existence of these characters by means of "alternative characters" or materialized "symbol" in the process of reading and watching, and through the media, these characters show their meaning. As Stuart Hall said in the discussion of the role of "reproduction", "the process of meaning production is to use media to express an object or meaning that is not present."

The alternative character indicates the presence of the meaning of the absentee. In literary texts, the author usually sets up an alternative character to assume the meaning and function of a missing person. In the representative novels of Charlotte Bronte, although the image of the father is "absent", there are also several men who are older than the heroine and have a higher status and distinctive personality. For example, William Clemworth in The Professor, Rochester in Jane Eyre, Robert Moore in Shirley, and Paul Immanuel in Villette. These masculine and tyrannical male images have a high degree of similarity with the image of the father in the literary tradition, and are actually substitutes for the father's role. The tradition of patriarchal culture has not disappeared because of the absence of the father's image, but is hidden in the heart of alternative characters - several male images, affecting other roles. A similar situation exists in McEwan's novel Atonement. The author places the "absence" of his father's image in a background of war and violence full of masculinity. For children who are underage or just growing up, the loss of father's love itself has a great negative impact on growth and future destiny. The shadow of war undoubtedly makes the situation worse. The humanity in this context is sure to even more cruel and true. Paul Marshall in the novel is a typical endorsement in the patriarchal society. This person is full of possessive desire for money, women and power, having a far-reaching impact for the development and destiny of other characters in the novel.

The materialized "symbol" implies the presence of meaning. The function of the character to promote the narrative is not necessarily realized by the presence of the image of the body or the voice. The item belonging to someone can also be the symbol of its owner. The "ex-wife" in the film "Butterfly Dream" — Rebecca has not appeared in the camera even though she has died, but audience feels that she is always "present" (the English title is "REBECCA"). There are items in the manor that are marked with the abbreviation "R", such as letterheads, memo pads, napkins, pillows, etc., which remind us of her existence all 
the time. In addition, Mrs. Danvers, who is spooky, is Rebecca's "dead loyalty" and serves as the spokesperson for Rebecca living in the world. The plot in the first half of the film outlines a generous and charming aristocratic woman, and contrasts with the innocent weakness of Mrs. Derwent. The male protagonist's gloomy and weak character behind graceful appearance, his behavior, and the final doom of Mandeli manor in the fire all reflect "meaning of presence" of the dead Rebecca. In "Raise the Red Lanterns", although the Master Chen Zuoqian is mysteriously turned into "absence" by the director, the audience can still feel the feudal patriarchy and manus from the symbolic symbols of the film, such as lanterns, leg beating, iron house and water well. The strong symbol of the husband's right is present. This kind of presence is like a big net shrouded in a closed and deep courtyard. The tragedy of the fate of several concubines in the film is directed by the vague "ruthless character" that is not present.

Present as a spiritual symbol. A person who is absent in some form has not only existed as a person in the physical sense, but has become a "spiritual symbol" with a symbolic meaning. In "Bodyguards and Assassins", "Sun Yat-sen" has always been shown in the film with his back, silhouette and voice, but appears at the last moment of the film. It is difficult to say whether this kind of handling is good or bad. But it is certain that even if there is no front image and "absent" to the end, the symbolic meaning of "China's tomorrow" from the plot and details of the film can be understood. Sun Yat-sen's classic hats and costumes are the hallmarks of his dominant existence, and its sound image, especially the classic lines in the film, "the desire for civilization has to go through the pain of civilization, and the pain, we call it revolution" also shows the powerful spiritual appeal of the characters. At the end of the film, those forgotten victims such as Li Zhongguang and Asi finally get a monumental naming and martyrs identity. In the great historical mission of protecting Sun Yat-sen's "spiritual symbol", they realize the value and significance of life and at the same time profoundly embody the "present" significance of Sun Yat-sen as a revolutionary pioneer.

\section{CONCLUSION}

Throughout the examples listed above, in many art texts, the "absence" of a character can be understood as the challenge of female consciousness to traditional patriarchal values, especially in literary works. However, during the reading and viewing process, it can be found that the strength and significance of this challenge is also limited. Some "absence" treatments both have not eliminated "patriarchal power" and other meanings; in contrast, they have added the tension of these meanings, making the meaning of "presence" more impressive, more deeply rooted, and more powerful. After all, the "social scenes", which is the mysterious foundation of the language expression and behavioral framework, always exists. The social scenes of different eras are a powerful rule system that regulates the speech and behaviors of the people living in it in an imperceptible state. When Tian Huiqun analyzed five films, such as " new feminism director" Li Yu's "Apple" and
"Double Xposure", he described the "absent males", the common of these several films, as "the demons in the bottle" to emphasize their impacts on the female protagonist. But at the same time, he also said that "although the five films have presented the life and destiny of the female protagonist, it is impossible to name them as feminist films in the true sense. The conscious path of women, both in reality and in the dreams created by movies, is still far and ambiguous. In short, the "absence" of characters in narrative texts such as novels and movies does not mean the meaning they carry is really absent, but in the case of non-dominant existence, they show their meanings in symbolic form such as deformation, marked nature, or a substitute character of "image-likeness" or as a spiritual symbol to promote the development of the storyline and affect the survival and destiny of other characters.

\section{REFERENCES}

[1] Huang Guangfang. Present Man of Absence: the "Shadow Character" Image of Menthus in "Odyssey" [J]Home Drama2015(22):265-266. (in Chinese)

[2] Lu Puling. Character: Fictional Life - On Concept of Narrative Characters [J]. Jiangxi Social Sciences, 2014, 34(09):216-221. (in Chinese)

[3] Zhang Yun. Transient Heather Flowers on the Wasteland - The Bronte Sisters Biography [M].Beijing: China Federation of Literary and Art Circles Publishing Houses, 2002. (in Chinese)

[4] Daniel Dayan, Chen Xihe. The Guiding Code of Classic Movies [J]. Contemporary Film, 1987 (04): 17-26. (in Chinese)

[5] Zhao Yiheng. The Paradox of Symbolic Process and Its Incomplete Variants [J].Signs and Media, 2010(01):3-21. (in Chinese)

[6] Stuart Hall. Translated by $\mathrm{Xu}$ Liang and $\mathrm{Lu}$ Xinghua. Characterization [M].Beijing: Commercial Press, 2005 edition, page 4.

[7] Tian Huiqun. The Devil in the Bottle: The Male Who Is Not Present - The Psychoanalysis of Li Yu's Movies[J]. Contemporary Film, 2014(05): 64-68. (in Chinese) 